Critical success conditions

of collaborative methods: a

comparative evaluation of

transport planning projects

Journal Article

Author(s):

Walter, Alexander I.; Scholz, Roland W.

Publication date:

2007-03

Permanent link:

https://doi.org/10.3929/ethz-b-000003059

Rights / license:

In Copyright - Non-Commercial Use Permitted

Originally published in:

Transportation 34(2), https://doi.org/10.1007/s11116-006-9000-0 


\title{
Critical success conditions of collaborative methods: a comparative evaluation of transport planning projects
}

\author{
Alexander I. Walter · Roland W. Scholz
}

Published online: 27 September 2006

(C) Springer Science+Business Media B.V. 2006

\begin{abstract}
This paper explores critical success conditions of collaborative planning projects in the area of urban transport, evaluating the impact of new collaborative methods, instruments and processes on project performance. Hypothesis building is based on a comparative, empirical research design, rather than on deductive theory construction. Potential critical success conditions are derived from literature. Based on five urban transport planning projects in Gothenburg (Sweden), London (United Kingdom), Milwaukee (United States), Tokyo (Japan) and Mexico City (Mexico), a rough set analysis of the five cases reveals validated success conditions, which can be used for formulating hypotheses for further research or for policy and process improvement. The results suggest that a dedicated management of the multi-actor network, a high diversity of actors, as well as an extensive use of knowledge integration methods in combination with a high network density are critical success conditions of these planning processes. Surprisingly, the extensive use of unilateral methods also showed to be an important success condition. The traditional role of the planner will have to be complemented with the expertise of network and methodology management. The authors conclude that rough set analysis can be a valuable addition to narrative, single-case analysis of collaborative urban transport planning processes.
\end{abstract}

Keywords Project evaluation · Multi-actor planning · Participatory planning · Rough set analysis · Critical success conditions · Collaborative planning · Knowledge integration

\section{Introduction}

Many researchers consider transportation as a critical factor for urban sustainability. It causes negative local effects such as noise and pollution (cf. Kemp and Rotmans

\section{A. I. Walter $(\bowtie) \cdot R$. W. Scholz}

Institute for Environmental Decisions (IED), ETH Zurich, Universitätsstrasse 22, 8092 Zurich, Switzerland

e-mail: alexander.walter@env.ethz.ch 
2002), and uses $30 \%$ of the primary energy in the EU (Commission of the European Union 2001, p. 124). Its infrastructure demands much of the scarce urban space (cf. Henson and Essex 2003). However, urban residents consume fewer resources than peri-urban residents (Handy 2005). Thus, urban transport can also be seen as a potential driver of sustainable development (Banister 2000).

Against this background, the requirements for transport planning have changed in the last decades (Goetz and Szyliowicz 1997; Low and Gleeson 2001; Meyer 2000), such that it has to acknowledge the interactions between transport solutions and sustainable urban development. Many recent publications deal with new approaches to transport planning, proposing new processes, methods, and instruments for planning processes (Booher and Innes 2002; Davidson 1996; Healey 1998; Henson and Essex 2003; Kane and Del Mistro 2003; Kemp and Rotmans 2002; Loukopoulos and Scholz 2004; Nijkamp et al. 1997; Szyliowicz 2003; Talvitie 2001; Tapio and Hietanen 2002; Ward 2001; Willson 2001; Zegras et al. 2004). Most of these publications agree that planning has become a public issue (e.g. Banister 2003, p. 249). The planning process takes place in a multi-actor network. Collaborative interaction between the actors becomes more important (Booher and Innes 2002; Vigar 2000). The power of participating actors also requires a focus on learning and the acceptance of a constructivist view (Chermack and van der Merwe 2003). Willson (2001) and others call this a shift from a scientific to a communicative rationality.

Additionally, most authors agree that the inherent complexity of the issue requires a new planning methodology (cf. Lo and Wong 2002; Lo and Wong 2004). There are also some new transport policy instruments proposed, which link different aspects of transport planning (e.g. the integration of different modes of transport or public-private partnerships).

Methodologically, most new approaches presented are deductive models, which have to prove their usefulness in real-life planning processes (Szyliowicz 2003). Their usefulness is demonstrated based on one single case, following a qualitative and narrative approach to the reflexion on planning processes. This approach delivers important qualitative insights into how collaborative planning processes can be improved. The works of, among others, Patsy Healey, Jean Hillier, and Judith Innes are important examples.

Still, planning research needs a pluralistic approach to capture the pluralism of planning practice itself (Myers and Banerjee 2005). There is a need to obtain a "critical distance" for a "broader analytical view" on planning processes in order to be able to make explanatory statements about planning processes (Yiftachel and Huxley 2000, p. 910). With our approach, we do not propose to "re-rationalize" the planning process or to go back to the old ideal of a "general planning theory" (Alexander 1998). Rather, we see a need for comparative evaluation approaches to planning processes (Brody and Highfield 2005; Laurian et al. 2004), as one form of obtaining "critical distance". Comparative approaches deliver different insights than narrative approaches, allowing inductive conclusions on general and specific aspects of planning processes (Gissendanner 2003).

We concentrate in this study on the comparison of methods, processes and instruments of collaborative planning, applied in different cultural and political contexts. Our goal is to derive critical success conditions (CSCs) only for the mentioned field, in order to learn about the benefits of different collaborative planning methods and approaches. Other important factors, such as the local "planning 
culture" or "planning style" (Innes and Gruber 2005), are better analysed with a narrative approach and are not the subject of our research.

Critical success "conditions" or "factors" have been defined as necessary conditions for success (Jenster 1987; van Egmond et al. 2003). We will show in our comparative study, which CSCs from the above mentioned approaches are necessary preconditions for a successful collaborative planning project in urban transportation in the analysed cases. This also serves to demonstrate the benefits of a comparative approach for the reflexion on planning processes. Based on a set of five case studies, we deduce relationships between the status of the postulated CSCs and the performance of the cases. Eisenhardt (1989) indicates that linkages between quantitative and/or qualitative variables or indicators in a framework model, can be achieved using a cross case analysis of a sample of 5-10 cases. Yin (1984) refers to this kind of research approach as a "groundbreaking case study." The deduced relationships take the form of "if-then"-rules and are valid within the "mental model" of the analysis and analysed dataset. Causality cannot be claimed, because we do not go into the detail of the mechanisms of action. Nevertheless, the comprehensive qualitative information about the cases will be used in the discussion and conclusions to derive some causal hypotheses.

The paper is organised as follows. Section 3 provides an introduction to the method used for the cross-case analysis. In Section 4, the analytic-evaluative framework for the assessment of the CSCs is presented. The cases are introduced in Section 5. Section 7 presents the results of the analysis and the corresponding discussion. Conclusions on the results and on the applicability of the methods are drawn in Section 8.

\section{Method}

In our type of cross-case comparison, standard statistical approaches are difficult to apply because of the relatively low sample size (Glass et al. 1994). We, therefore, adopt rough set analysis (RSA), a multivariate classification method that aims to detect deterministic rules in a dataset. The approach was developed by Pawlak (1991). It has already been used in research on urban transport (cf. Baaijens and Nijkamp 2000; van Egmond et al. 2003). It is a transparent method, designed to help the researcher in discovering patterns in a data set and setting them apart from contingencies. It does not prove any form of causality, but it can suggest new hypotheses where to look in detail for causal mechanisms of action. The advantage of RSA is that it delivers robust results for fuzzy information that can easily verified with the raw data.

The dataset for analysis consists of a matrix of cases, which are represented by attributes (i.e., independent variables) and by decision variables (i.e., dependent variables). The attributes represent the available knowledge on the cases, while the decision variables represent a classification of the cases. The process of RSA can then be divided into a number of substeps. The first is the mapping of case information into an information table (Table 3). The following steps are the completion of data, followed by a discretisation, especially of interval and ratio-scaled values. In the step of rule generation, the algorithm starts with a set of all possible rules and performs a search for the best rules. Rules take the form of if-then-statements (e.g. IF attribute $\mathrm{X}=\mathrm{A}$ AND attribute $\mathrm{Y}=\mathrm{B}$ THEN decision variable $\mathrm{Z}=\mathrm{C}$ ). Rules 
can be formed combining any number of attributes. The rules have to be complete, i.e. they have to include all cases with the decision variable value, and consistent, i.e. cases with other values cannot be included. In the last step, the rule filtering, the amount of rules is limited by defining a maximum length (based on the number of attributes in one rule) and minimum strength (based on the number of cases included in the rule).

The goal of RSA is twofold: to predict the value of the decision variables for a given case and to represent the knowledge in the dataset in an understandable format of rules. The advantage of RSA is that it can process low scales of measurement and small sample sizes while still delivering meaningful results (cf. Olkowski and Skowron 1998; Pawlak 1991).

Methodologically, this paper follows the approach Nijkamp et al. (2002) applied to a comparative evaluation of public-private partnership projects. The attributes in our case consist of CSCs of the cases, which we derived from transport planning research literature. The decision variables represent the performance of the cases. Therefore, the "usage of participatory methods" represents a CSC and an attribute, whereas the "achievement of a consensus between the stakeholders" is a performance indicator and consequently a decision variable.

\section{The analytical-evaluative framework}

Comparing unfinished projects of differing sizes, goals, and participants is a difficult task (cf. Berechman and Paaswell 2005, p. 225; Colebatch 1995). Van der Meer and Edelenbos (2002) state that abstract criteria would be needed in order to ensure applicability. We, therefore, used abstract performance indicators and CSCs on an ordinal scale level with two to three different values. This represents a specific tradeoff for this study between accuracy and generality of the estimations (cf. Gissendanner 2003). The more detailed the scales are defined, the more difficult it is for RSA to find consistent patterns, which eventually lead to new insights about the dataset.

\subsection{Performance indicators}

We selected efficiency, effectiveness, and relevance as performance indicators, all of which are frequently used criteria for the evaluation of planning projects (cf. Bots and Lootsma 2000). We also took into account the legitimacy of the process (cf. Dror 1997). We are aware that at least some of these criteria conflict with each other (Dahl 1994), but since we do not aggregate them for an overall evaluation score, this approach is possible.

Relevance was assessed as the accuracy of the measure that was finally proposed in regard to targeting the postulated problem. The better the measure targeted the problems defined in the project, the greater the relevance. Effectiveness, or the ability of the project to produce an effect, was measured by how well the proclaimed goals of the project where attained by the measures implemented. Relevance and effectiveness are therefore distinguished by the difference in the problem and goal definitions of the projects, respectively.

The efficiency as the relation of means and outcomes is here defined as the time between the first multi-actor problem recognition process, and the beginning of the implementation phase. The legitimacy of the process was assessed by the degree of 
consensus reached by the five most involved actors. The total performance represents an overall rating of the case's performance, incorporating an overall judgement derived from the qualitative parts of the stakeholder interviews (Walter and Scholz forthcoming) (Table 1).

\subsection{Critical success conditions (CSCs)}

\subsubsection{Interaction and organisation}

The Level of involvement distinguished between information, consultation, and deliberation, analogous to the 'ladder of participation' (Arnstein 1969; Petts 2001). We expected a high involvement to lead to more relevant results as well as to increase effectiveness, although such processes typically take longer (Healey 1998; Susskind and Cruikshank 1987).

Standard planning procedure indicated whether the planning process was part of the standard legislative procedure or whether it was specially adapted. We expected that "tailor-made" processes would increase the total performance of the projects through their adaptation to the specific circumstances (Mayer 1995).

Dedicated network management indicated whether there is an explicit and autonomous entity responsible for the co-ordination of the actor network. We expected it to have a strong positive influence on all performance indicators through more effective interaction of stakeholders (Davidson 1996; Willson 2001).

Actor diversity measured the different resources the actors could supply to the process: specific knowledge, authority, or financial resources. We expected a higher diversity to lead to a higher availability of diverse resources, thus making the process more relevant, efficient and effective (Ward 2001; Willson 2001).

Actor network density was measured according to Scott (2000), based on the intensity of communication between the five most important actors. We postulated that a high density would enable a higher degree of understanding between the actors, thus leading to more relevant and effective solutions, following the ideas of Booher and Innes (2002).

Network structure differentiated between hierarchical and heterogeneous networks. Hierarchic networks are characterized by a clear "chain of command", while heterogeneous networks have distributed and task dependent power relationships. We estimated heterogeneous networks to lead to a higher relevance of the projects (cf. Ward 2001).

To account for the effect of different kinds of participants, we classified them according to the diversity measurement (Walter and Scholz forthcoming): municipal, city, regional, and national administrations; business associations; companies; the public, including public interest groups and NGOs. The NGOs where combined with

Table 1 The codification matrix for the performance Indicators

\begin{tabular}{lllll}
\hline Performance Indicators & Short name & 1 & 2 & 3 \\
\hline Measure relevance & Relevance & High & Partial & Low \\
Goal attainment & Attainment & Full & Partial & None \\
Length of process & Length & $<10$ years & $10-30$ years & $>30$ years \\
Consensus of stakeholders & Consensus & Yes & No & None \\
Total performance & Performance & Full & Partial & Non \\
\hline
\end{tabular}


the public, because their interests, relationships and resources where very similar to the general publics opinion in the cases. The administrative levels were differentiated because they took on different roles in the same projects. The municipal administration was defined as the level of administration below the city level, partitioning the city.

\subsubsection{Instruments and methods}

Unilateral, bilateral and multilateral methods were assessed according to Bickerstaff and Walker (2001). Unilateral methods are one-way communication methods (e.g. surveys, leaflets). Bilateral methods involve a dialog (e.g. interviews, consultation processes). Multilateral methods require at least three different parties (e.g. round tables, scenario workshops).

The methods used in a planning process are crucial for the integration of different knowledge bases (Kane and Del Mistro 2003; Zegras et al. 2004; Wiek and Binder 2005; Scholz et al. 2006; Stauffacher et al. 2006). There has been much research specifically examining knowledge integration methods in planning (Scholz and Tietje 2002; Hansmann et al. 2003; Loukopoulos and Scholz 2004). We expected multilateral methods to have the highest impact on total performance (Scholz and Tietje 2002).

Types of knowledge exchanged: We rated each method used according to its potential to integrate different types of knowledge: regarding the definition of the problem and the perception of the current situation (system knowledge), the measures to use (transformation knowledge), and the goals of the project (goal knowledge) (Mogalle 2001). We postulated that it is important to integrate all types of knowledge in order to enable a relevant and effective process (Willson 2001; Tapio and Hietanen 2002; Szyliowicz 2003).

Public and private transport in the same measure considers whether public and private transport are packaged into one measure, which is considered to increase efficiency, effectiveness, and consensus on the measures (Kemp and Rotmans 2002; Langmyhr 2001).

Governmental subsidies recorded whether the instruments used contain governmental subsidies for specific transport modes or technologies, which was expected to decrease efficiency, relevance, and effectiveness (Karlaftis and McCarthy 1997).

\subsubsection{Issues}

To test whether the issue at hand of the project had an influence on the outcome, we included the involvement of the project with the issues congestion, city development, pollution, public transport and equity/accessibility into the analytical-evaluative framework.

\subsubsection{External conditions}

We included some external conditions to take into account their influence on project performance. Van Egmond et al. (2003) and Banister (1996) consider city size and city density as the most important external conditions to be controlled in this type of analysis. 
It has to be noted that the framework (cf. Table 2) is not an instrument for sufficiently describing transport planning projects. It also includes redundant descriptions. This is not problematic insofar as each CSC is tested independently. Combinations of similar CSCs can easily be identified as redundant if they appear in the resulting rule set.

\section{The cases}

As we strove for generalized CSCs, we selected a broad range of projects. They were selected to be in the area of urban transport; to be completed or near completion; to have substantial scope with at least five actors and at least one public and one private actor; and to have a multi-actor approach to planning.

At least three key persons from different institutions were interviewed for each case in the end of 2002. In Tokyo, one interviewee had to cancel on short notice. All interviews were recorded and transcribed (Walter and Scholz forthcoming). The five most involved actors were identified by the number of nominations from the interview partners.

Table 2 The codification matrix for the dimensions of planning processes considered

\begin{tabular}{lllll}
\hline Dimensions and & Short name & 1 & 2 & 3
\end{tabular}

corresponding CSCs

(a) Interaction and organisation

Level of involvement

Standard planning procedure

Involvement Information Consultation Deliberation

Dedicated network management

Actor diversity

Standard Yes

Yes

Actor network density

$\begin{array}{ll}\text { Dedicated } & \text { Yes } \\ \text { Diversity } & \text { High }\end{array}$

Network structure

Municipal Administration

City Administration

Regional Administration

National Administration

Business Associations

Companies

Public

Density

High

No

No

Average Low

Structure Hierarchical

Municipal Yes

City Yes

Low

(b) Instruments and Methods

Unilateral methods

Bilateral methods

Multilateral methods

Types of knowledge exchanged

Public and private transport

Regional

Yes

Heterogeneous

National Yes

Business Yes

Companies Yes

Public Yes

No

No

No

No

No

No

No

in the same measure

Governmental subsidies

\begin{tabular}{|c|c|c|c|}
\hline Unilateral & None & $1-2$ & 3 or more \\
\hline Bilateral & None & $1-2$ & 3 or more \\
\hline Multilateral & None & $1-2$ & 3 or more \\
\hline Knowledge & Transformation & Also goal & Also problem \\
\hline Same & Yes & No & \\
\hline Subsidies & Yes & No & \\
\hline Congestion & Important & Marginal & Not an issue \\
\hline Development & Important & Marginal & Not an issue \\
\hline Pollution & Important & Marginal & Not an issue \\
\hline Publictransport & Important & Marginal & Not an issue \\
\hline Equity & Important & Marginal & Not an issue \\
\hline Size & Smaller City & Bigger City & Megalopolis \\
\hline Citydensity & Low $(<3,000)$ & High $(>3,000)$ & \\
\hline
\end{tabular}

(c) Issues

Congestion

City development

Pollution

Public transport

Equity/Accessibility

(d) External conditions

City size

City density

Citydensity

Low $(<3,000)$ 
While the performance indicators were assessed using an expert approach (cf. Nijkamp et al. 2002, p. 1871), the attributes were assessed using a qualitative database consisting of the interviews, publications, and reports about the projects, deriving a score through comparative analysis. Since the measurement scale is low, we expect the information to be robust enough on this scale level to draw conclusions based on the data (cf. Baaijens and Nijkamp 2000; Nijkamp et al. 2002; Gissendanner 2003; van Egmond et al. 2003).

\subsection{Gothenburg-mediation process of ring road construction}

Gothenburg with its 778,000 inhabitants straddles the Göta River. There are only three ways to cross the river. By the 1990s, the city suffered from these insufficient connections. Therefore, a mediation process between state and city was initiated to construct a ring road (cf. Falkemark 1999). The participants involved were the state of Sweden, who called upon a private mediator, and several different regional representative organisations. Initially, traffic experts from the Gothenburg traffic department and the national road administration also took part.

\subsection{London-congestion charging in the inner city}

Inner London has a population of 2.7 million and a population density of 8,600 per $\mathrm{km}^{2}$ (Greater London Authority 2001). The London congestion-charging scheme has been developed in the record time of only 18 months (Banister 1996, 2003). An extensive stakeholder consultation and public outreach process was conducted, with the most important stakeholders being the Greater London Authority, Transport for London, the London business associations, car user associations, the London boroughs and the public.

\subsection{Mexico City - restructuring the bus system}

The Mexico City Metropolitan Area has about 17.9 million inhabitants with a density of 12,260 inhabitants per $\mathrm{km}^{2}$ in the urbanized area. About 20 million trips are made by public transport per normal workday, the vast majority in buses (cf. Molina and Molina 2002). In 2001, the city government initiated a program to improve the bus service: the substitution of the old "Microbuses," with modern, diesel-driven buses with a higher seating capacity. The most important participants in this project were the city's secretary of the environment, the secretary of transport, the metropolitan commission, bus manufacturers, banks, and bus driver organisations.

\subsection{Milwaukee-introduction of downtown fixed rail public transport}

Milwaukee (600,000 inhabitants and a density of 2400 inhabitants per $\left.\mathrm{km}^{2}\right)$ is undergoing a major change from an industrial centre to a mixed-use area of working, living, and leisure (Milwaukee Economic Development Cooperation 2001). In 1994 the central actors in the city area started devising a new public transport system. The project included innovative technology, economic considerations, social concerns, and ecological issues. The most important participants were authorities from all 
levels of administration, business representatives, a dedicated case manager, the manufacturer of the transport system, and the public.

\subsection{Tokyo-introduction of compressed natural gas powered vehicles}

Tokyo city centre is home to 8.21 million persons, with a density of about 13,211 inhabitants per $\mathrm{km}^{2}$. In August 1999, the Tokyo government started a campaign to replace the biggest contributors to the city's pollution problem, diesel vehicles, with more environmentally friendly natural gas powered vehicles. The campaign started very slowly, due to coordination difficulties between actors (Yarime 2004). The campaign, which included a round table discussion on the introduction of natural gas powered vehicles (NGVs), had the following participants: The Tokyo metropolitan government, NGV manufacturers, NGV users, and gas companies.

\section{Discussion}

The application of RSA to the information table (cf. Table 3) using the ROSE2 software program (Predki et al. 1998) yields the rule set listed in Table 4. Obviously, the interpretation is valid to the extent that the case studies considered offer a fair representation of urban transport planning projects. For all rules, the strength of the RSA approximation is equal to 1, which means that they are all applicable to each one of the cases analysed.

Rules that could be linked using logical operators (AND and OR) were merged into one single rule to increase clarity. Rules with more than two attributes or rules derived on the basis of only a single case were omitted. Two exceptions of the latter were made, in order to show that a set of rules explains all values of a CSC (rules 6-8 and 27-29). Rules that were obviously derived from random relationships between the cases were omitted. This concerned several rules that combined attributes from the "Issues" dimension with the "Methods and Communication" dimension. It derived from a random relationship of two projects. The relationship could not be confirmed to have any causal mechanism or other reasoning behind it, and the rules were therefore omitted.

The cases seem to be divisible into three groups, corresponding to the total performance (Table 3): London and Milwaukee, Tokyo and Mexico City, and Gothenburg (cf. Fig. 1). This seems a plausible result, as we evaluated the cases with respect to their performance. The rules should reflect this analytic categorization.

London and Milwaukee represent a type of case with high values in almost all performance indicators (cf. Table 3). Surprising is the extensive use of unilateral methods, which seems to have been necessary for the high performance of the cases (rule 17). In both cases however, great effort was put also into the process of integrating the diverse stakeholders into a multi-actor network, and using advanced methods of knowledge integration for generating a common view of the situation. Also, all actors with a perspective on sustainable urban development were included in the process (the public, municipal administration, and business associations).

Mexico City and Tokyo represent cases with medium performances. Neither the municipal administration, nor business associations, nor the public were included in the process, leading to a lack of consensus (rules 10,13,16). This group is characterized by a missing awareness of the implications of multi-actor planning. The 
Table 3 (a) The information table on CSCs. For an explanation of the codification see Table 2; (b) The information table on performance indicators. ( $\mathrm{GO}=$ Gothenburg, $\mathrm{LO}=$ London, MX = Mexico City, MW = Milwaukee, $\mathrm{TO}=$ Tokyo)

$\begin{array}{llllll}\text { Short Name } & \text { GO } & \text { LO } & \text { MX } & \text { MW } & \text { TO }\end{array}$

(a) Domains and corresponding CSCs

A. Interaction and Organisation

Level of involvement

Standard planning procedure

Dedicated network management

Actor diversity

Actor network density

Network structure

Municipal Administration

City Administration

Regional Administration

National Administration

Business Associations

Companies

Public

B. Instruments and Methods

Unilateral methods

Bilateral methods

Multilateral methods

Types of knowledge exchanged

Public and private transport

in the same measure

Governmental subsidies

C. Issues

Congestion

City development

Pollution

Public transport

Equity/Accessibility

Involvement
Standard
Dedicated
Diversity
Density
Structure
Municipal
City
Regional
National
Business
Companies
Public

2

2

3

2

1

2
2

2
1

1
1

1

2

\begin{tabular}{|c|c|c|c|c|}
\hline Unilateral & 1 & 3 & 2 & 3 \\
\hline Bilateral & 2 & 3 & 2 & 3 \\
\hline Multilateral & 1 & 2 & 2 & 3 \\
\hline Knowledge & 1 & 3 & 3 & 3 \\
\hline Same & 1 & 1 & 2 & 2 \\
\hline Subsidies & 2 & 2 & 1 & 2 \\
\hline Congestion & 1 & 1 & 2 & 2 \\
\hline Development & 3 & 3 & 3 & 1 \\
\hline Pollution & 3 & 3 & 2 & 3 \\
\hline Publictransport & 2 & 2 & 1 & 1 \\
\hline Equity & 3 & 2 & 2 & 2 \\
\hline Size & 1 & 2 & 3 & 1 \\
\hline Citydensity & 1 & 2 & 2 & 1 \\
\hline Relevance & 3 & 1 & 2 & 1 \\
\hline Attainment & 3 & 1 & 2 & 2 \\
\hline Length & 2 & 3 & 1 & 2 \\
\hline Consensus & 2 & 1 & 2 & 1 \\
\hline Performance & 3 & 1 & 2 & 1 \\
\hline
\end{tabular}

\section{External Conditions}

City size

City density

(b) Performance indicator

Measure relevance

Goal attainment

Length of process

Consensus of stakeholders

Total performance

indicator

ged

\begin{tabular}{|c|c|c|c|c|}
\hline Unilateral & 1 & 3 & 2 & 3 \\
\hline Bilateral & 2 & 3 & 2 & 3 \\
\hline Multilateral & 1 & 2 & 2 & 3 \\
\hline Knowledge & 1 & 3 & 3 & 3 \\
\hline Same & 1 & 1 & 2 & 2 \\
\hline Subsidies & 2 & 2 & 1 & 2 \\
\hline Congestion & 1 & 1 & 2 & 2 \\
\hline Development & 3 & 3 & 3 & 1 \\
\hline Pollution & 3 & 3 & 2 & 3 \\
\hline Publictransport & 2 & 2 & 1 & 1 \\
\hline Equity & 3 & 2 & 2 & 2 \\
\hline Size & 1 & 2 & 3 & 1 \\
\hline Citydensity & 1 & 2 & 2 & 1 \\
\hline Relevance & 3 & 1 & 2 & 1 \\
\hline Attainment & 3 & 1 & 2 & 2 \\
\hline Length & 2 & 3 & 1 & 2 \\
\hline Consensus & 2 & 1 & 2 & 1 \\
\hline Performance & 3 & 1 & 2 & 1 \\
\hline
\end{tabular}

planning process still followed the old general comprehensive paradigm too much, instead of shifting towards collaborative planning.

The case of Gothenburg represents a failed planning process. The performance indicators rate very low. It is similar to Mexico City and Tokyo, with an even lower diversity (rule 8), which led to a low relevance of the proposed measure. Also, the total amount of knowledge integration methods used was very low. There were only knowledge integration methods used that focused on the measure, not on the goals of the actors or on a common view of the problem situation.

筩 Springer 


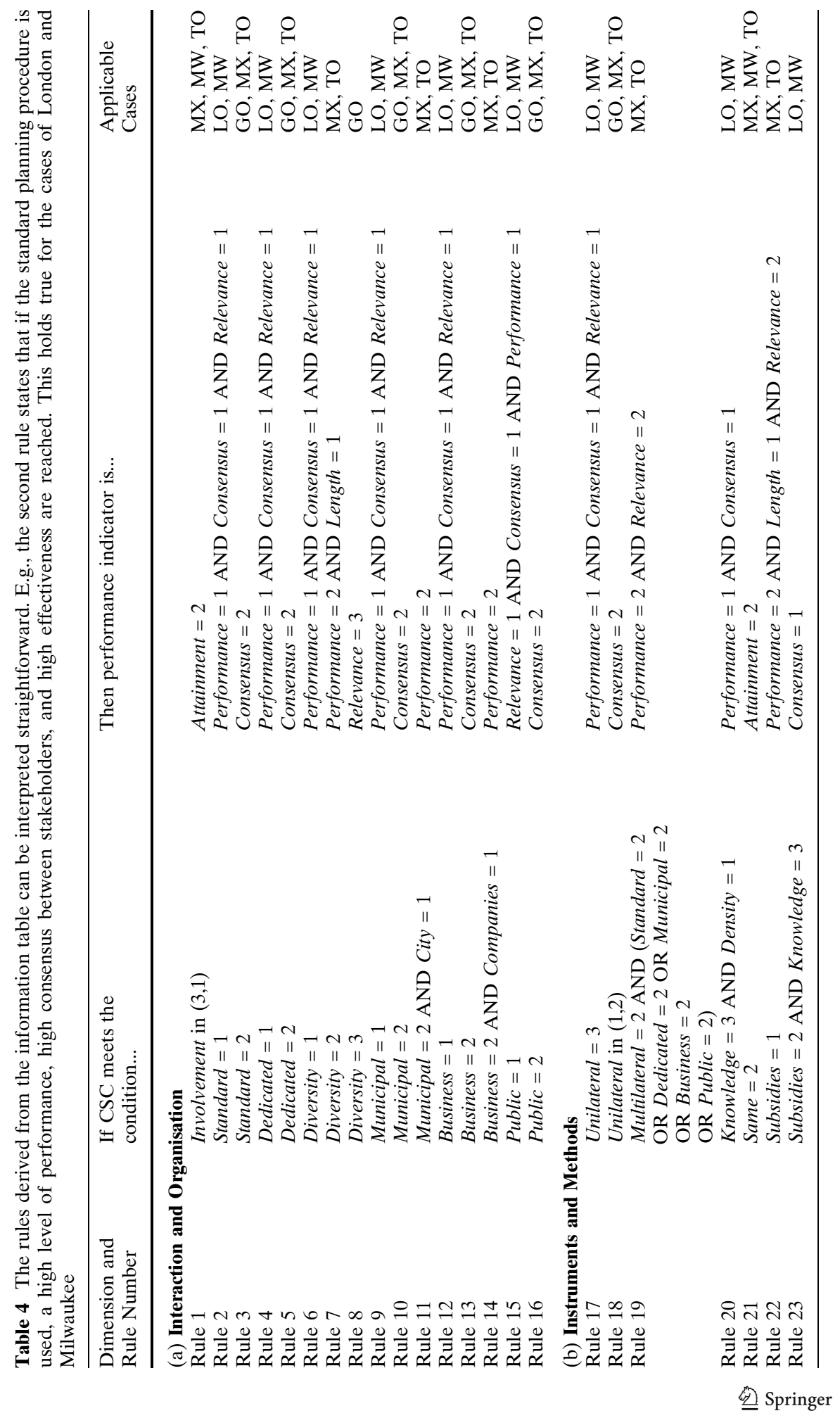




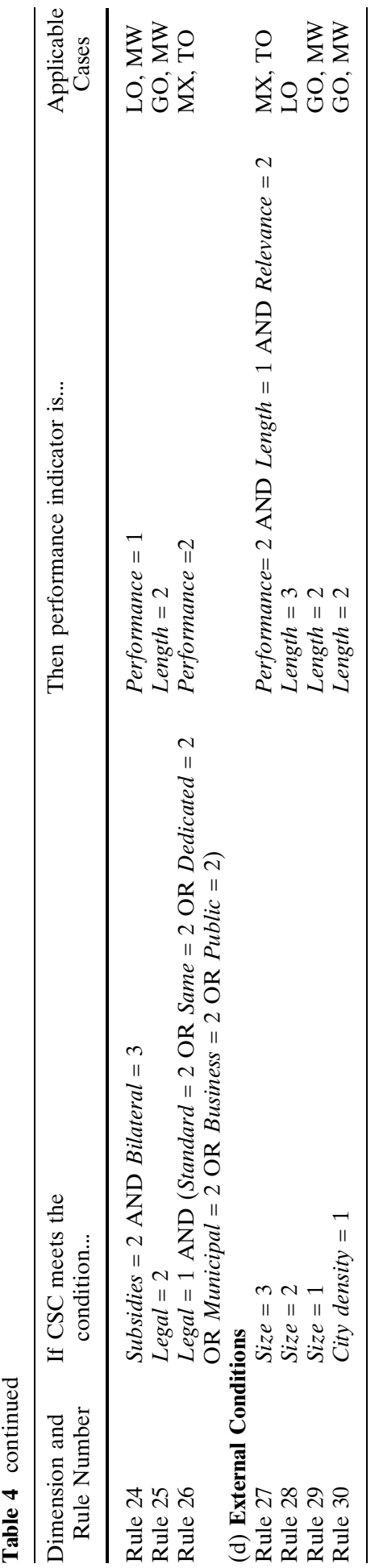

Springer 


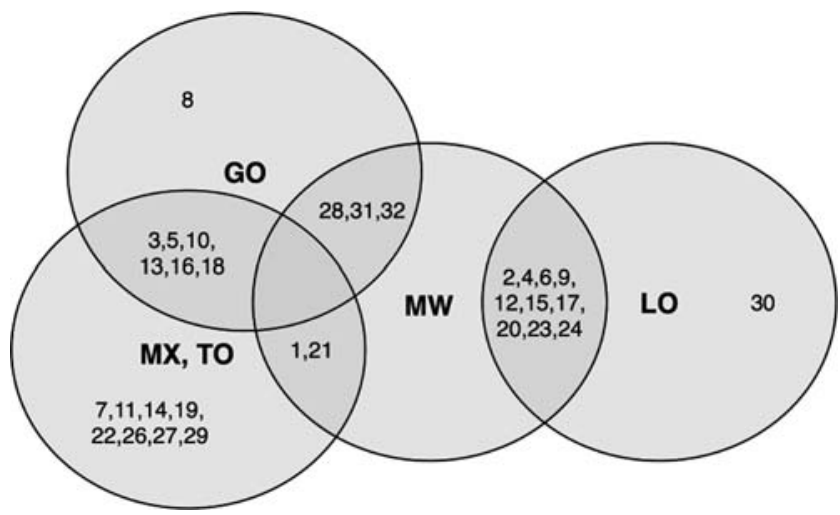

Fig. 1 The sets of rules attributable to the different cases (cf. Table 4; GO = Gothenburg, $\mathrm{LO}=$ London, $\mathrm{MX}=$ Mexico City, $\mathrm{MW}=$ Milwaukee, $\mathrm{TO}=$ Tokyo). These sets (grey circles) can be deducted from the "Cases" column of Table 4 and show for all rules (displayed by numbers), to which cities they are applicable

The most interesting linkage in the diagram is the similarity between Milwaukee's and Gothenburg's rules. Both rules (29 and 30) refer to external conditions: Milwaukee and Gothenburg have a similar size and density. Nevertheless, the performance of the two cases is very different.

The CSCs level of involvement and network structure did not result in any unambiguous rules and will thus not be discussed further.

\subsection{Interaction and organisation}

The standard planning procedure has a positive relation to total performance, relevance, and consensus (rules 2 and 3). This is in accordance with Desfor and Jørgensen (2004), who found that circumventing local planning practices raises conflicts with local stakeholders. It is contrary to our expectations and can be explained with the fact that "off-the-record" processes are often excluding stakeholders expected to have opposing interests (cf. Hillier 2000).

Dedicated network management has a strong influence (rules 4 and 5) on the total performance, consensus, and relevance. This supports our expectations and highlights the importance of communication and interaction in planning processes.

Actor diversity seems to be the strongest CSC, as it can differentiate best between the cases, although its effect is divided among different performance indicators. Still, one cannot conclude that the higher the diversity, the better the performance. A further increased diversity could very well have negative effects due to higher transaction costs (cf. Noteboom 2000).

Actor network density, together with an intensive process of knowledge integration, contributes to a high overall performance as well as to consensus (rule 20). The two CSCs seem to depend on each other. There is no direct influence on effectiveness or efficiency.

Participants: It is striking that the participation of regional, city, and national levels of administration is not related to the performance. Rule 11 states that if the municipal administration is absent from the process but the city administration is present, relatively poor project performance will result. The municipal 
administration seems to be a strong CSC, as well as the business associations and public CSCs. Not surprisingly, their influence on the consensus is strong (rules 9 and 10,12 and 13 and 15 and 16 , respectively).

\subsection{Instruments and methods}

Unilateral, bilateral and multilateral methods: unilateral methods have a strong influence on a range of performance indicators (rule 17). This runs contrary to many arguments for participatory methods. There was no clear relationship found for multilateral and bilateral methods, possibly because of the strong influence of the unilateral methods.

Types of knowledge exchanged: in order for knowledge integration to function, a high density of the actor network is necessary (see the CSC actor network density).

Public and private transport in the same measure: uncombined measures lead to partial goal attainment (rule 21), although it cannot be said whether effectiveness would be higher or lower with a combined measure.

Governmental subsidies have a negative impact on overall performance and relevance (rules 22-24). The influence is only in combination with other CSCs (cf. Table 4). A clear conclusion cannot be drawn based on the rule set.

\subsection{Issues}

There is no CSC from the issues dimension (see Table 3) in any rule. As such, it can be concluded that there is no influence of the concrete issue at hand on the planning process.

\subsection{External conditions}

The external conditions considered seem to be particularly related to the efficiency of the process (rules 27-30). This can be interpreted with the knowledge gathered in the case interviews: In relatively small cities like Milwaukee and Gothenburg, there is a higher political and institutional continuity, and projects can slowly build up. In big cities, sudden shifts in the political framework are more likely. Therefore, projects have to wait a very long time (like in London) until they can be implemented. If the political "window of opportunity" is there, the actors have to implement the project very quickly, as it was the case in London, Mexico City, and Tokyo.

\section{Conclusions}

The RSA returned similar CSCs for different performance indicators, which indicates a robustness of the model, because the performance indicators are most likely highly correlated. Considering the relatively small number of cases, it seems that RSA can deliver meaningful insights where other meta-analytic methods fail. Validity testing through application of the rule set to new cases should be the subject of further research.

We conclude that the application of RSA to the comparative evaluation of planning processes is a valuable addition to lessons drawn from single, in-depth case studies. Comparative methods like RSA, which focus evaluating specific parts of the 
planning process, can deliver new hypotheses which can then be verified through indepth case studies. Instrumental use of the rules can be made in the form of "best practice lessons," while at the same time allowing for conceptual use in theorybuilding. These results can then be re-applied to comparative designs. In this way the advantages of both methods can be combined.

Further research is needed to increase the reliability of the assessment process, possibly through a comparison of a self-evaluation with an expert evaluation. It would be interesting to conduct a RSA concerning other fields of possible CSCs, such as the cultural and contextual background of the cases. The limitations of RSA obviously lie in the relatively coarse mapping of the cases. Facing the current need for evaluative methods, we can see some potential in the method for developing it into a useful evaluation tool, if more stringent mapping of the data into an information table can be accomplished, without excessively increasing the time needed for the analysis.

Regarding the results of the analysis, CSCs in the areas of interaction, communication, methods, and instruments seem mainly to influence the relevance of the projects, the amount of consensus that can be reached between the stakeholders, and the total performance. They are therefore not sufficient to predict a project's outcome, but necessary to orientate the project towards its overall goals.

Our analysis clearly reveals the most relevant CSCs in the areas investigated and for the set of transport planning cases considered: an integration of the project into the standard planning procedure, a dedicated network management team, a high diversity of involved participants, and the inclusion of representatives from municipal administration, the business associations, and the public. These results correspond with the literature. The influence of the city administration will have to be clarified. The current results indicate that the municipal administration is more important, whereas the city administration could even have a negative influence on the performance.

Furthermore, a high density of the actor network combined with an extensive knowledge integration process was shown to be a CSC. This area should be addressed in further research, also considering the influence of diversity and cognitive distance (cf. Noteboom 2000).

Quite remarkably, the extensive use of unilateral methods also proves to be a success condition. It seems that this can "prepare the ground" for a planning process on a higher level of involvement. It is also a hint towards the "dark side of planning" (Yiftachel 1998): A plethora of information can be used to deliberately shift the perceptions of unsuspecting stakeholders.

These insights lead us to the proposition that, in multi-actor planning projects, performance is, to a certain degree, dependent on the process of interaction and communication, as well as on the methods chosen for knowledge exchange. It seems that a mix of high and low involvement is the "golden mean" between lengthy and ineffective processes on the one side and overruling top-down planning on the other. The planning process itself needs to be carefully managed. We argue in line with Booher and Innes (2002) that this requires additional competence, which could be introduced by specialised process managers. These new experts should combine the competence of mediators with problem structuring and problem solving methods in order to integrate the knowledge of traditional planners with the logic of practice.

Acknowledgements The research carried out was supported by the Volvo Research and Educational Foundations (VREF), and the Alliance for Global Sustainability (AGS). We thank Daniel Lang, Peter Loukopoulus, Arnim Wiek and the three anonymous reviewers for the valuable feed- 
back they gave on a previous version of this paper. A climate ticket from myclimate.org compensated for the $\mathrm{CO}_{2}$ emissions caused by the flights taken to conduct the interviews.

\section{References}

Alexander, E.R.: Doing the 'impossible': Notes for a general theory of planning. Environ. Plann. B: Plan. Design 25(5):667-680 (1998)

Arnstein, S.: A ladder of citizen participation. J. Am. Institute Planners 35(4):216-226 (1969)

Baaijens, S., Nijkamp, P.: Meta-analytic methods for comparative and exploratory policy research. J. Policy Model. 22(7):821-858 (2000)

Banister D.: Barriers to implementation of urban sustainability. 36th European congress of the European Regional Science Association: ETH Zurich, Switzerland (1996)

Banister, D.: Sustainable urban development and transport-a Eurovision for 2020. Transport Rev. 20(1):113-130 (2000)

Banister, D.: Critical pragmatism and congestion charging in London. Int. Social Sci. J. 55(2):249-264 (2003)

Berechman, J., Paaswell, R.E.: Evaluation, prioritization and selection of transportation investment projects in New York City. Transportation 32(3):223-249 (2005)

Bickerstaff, K., Walker, G.: Participatory local governance and transport planning. Environ. Plan. A 33(3):431-451 (2001)

Booher, D.E., Innes, J.E.: Network power in collaborative planning. J. Plan. Education Res. 21(3):221-236 (2002)

Bots, P.W.G., Lootsma, F.A.: Decision support in the public sector. J. Multi-Criteria Decision Anal. 9(1-3):1-6 (2000)

Brody, S.D., Highfield, W.E.: Does Planning Work? J. Am. Plan. Assoc. 71(2):159-175 (2005)

Chermack, T.J., van der Merwe, L.: The role of constructivist learning in scenario planning. Futures 35(5):445-460 (2003)

Colebatch, H.K.: Organizational meanings of program-evaluation. Policy Sci. 28(2):149-164 (1995)

Commission of the European Union (2001) White paper European Transport Policy for 2010: Time to Decide. Commission of the European Union, Brussels

Dahl, R.A.: A democratic dilemma. System effectiveness versus citizen participation. Political Sci. Quart. 109(1):23-34 (1994)

Davidson, F.: Planning for performance: requirements for sustainable development. Habitat Int. 20(3):445-462 (1996)

Desfor, G., Jørgensen, J.: Flexible urban governance. The case of Copenhagen's recent waterfront development. Eur. Plan. Studies 12(4):479-496 (2004)

Dror, Y.: Strengthening government capacity for policy development. Int. J. Tech. Cooperation 3(1):1-15 (1997)

Eisenhardt, K.M.: Building theories from case study research. Acad. Manage. Rev. 14(4):532-550 (1989)

Falkemark, G.: Politik, lobbyism och manipulation (Politics, lobbyism and manipulation). Nya Doxa, Stockholm (1999)

Gissendanner, S.: Methodology problems in urban governance studies. Environ. Plan. C 21(5):663-685 (2003)

Glass, G., MacGraw, B., Smith M.: Meta-Analysis in Social Research. Sage, Beverly Hills (1994)

Goetz, A.R., Szyliowicz, J.S.: Revisiting transport planning and decision-making theory: the case of Denver International Airport. Transport. Res., Part A 31(4):263-280 (1997)

Greater London Authority (2001) Transport strategy for London. Greater London Authority, London

Handy, S.: Smart growth and the transportation - Land use connection: What does the research tell us?. Int. Regional Sci. Rev. 28(2):146-167 (2005)

Hansmann, R., Mieg, A.H., Scholz, R.W., Crott, H.W.: Shifting Students' to Experts' complex systems knowledge: Effects of bootstrapping, group discussion, and case study participation. Int. J. Sustainability Higher Education 4(2):151-168 (2003)

Healey, P.: Building institutional capacity through collaborative approaches to urban planning. Environ. Plan. A 30(9):1531-1546 (1998)

Henson, R., Essex, S.: The development, design and evaluation of sustainable local transport networks. Int. Social Sci. J. 55(176):219-234 (2003) 
Hillier, J.: Going round the back? Complex networks and informal action in local planning processes. Environ. Plan. A 32(1):33-54 (2000)

Innes, J.E., Gruber, J.: Planning Styles in Conflict. J. Am. Plan. Assoc. 71(2):177-188 (2005)

Jenster, P.V.: Using critical success factors in planning. Long Range Plan. 20(4):102-109 (1987)

Kane, L., Del Mistro, R.: Changes in transport planning policy: changes in transport planning methodology?. Transportation 30(2):113-131 (2003)

Karlafti,s M.G., McCarthy, P.S.: Subsidy and public transit performance: A factor analytic approach. Transportation 24(3):253-270 (1997)

Kemp, R., Rotmans, J.: Managing the transition to sustainable mobility. In: Elzen B., Geels, F., Green, K. (eds), System Innovation and the Transition to Sustainability: Theory, Evidence and Policy. Edgar Elgar, Cheltenham (2002)

Langmyhr, T.: The rationality of transport investment packages. Transportation 28(2):157-178 (2001)

Laurian, L., Day, M., Berke, P., Ericksen, N., Backhurst, M., Crawford, J., Dixon, J.: Evaluating plan implementation. J. Am. Plan. Assoc. 70(4):471-480 (2004)

Lo, H.K., Wong, S.C.: Recent methodological advances in urban transportation planning. J. Urban Plan. Develop. ASCE 128(4):167-168 (2002)

Lo, H.K., Wong, S.C.: Emerging techniques for urban transportation planning. J. Urban Plan. Develop. ASCE 130(1):1 (2004)

Loukopoulos, P., Scholz, R.W.: Sustainable future urban mobility: using 'area development negotiations' for scenario assessment and participatory strategic planning. Environ. Plan. A 36(12):2203-2226 (2004)

Low, N., Gleeson, B.: Ecosocialization or countermodernization? Reviewing the shifting 'Storylines' of transport planning. Int. J. Urban Regional Res. 25(4):784-803 (2001)

Mayer, M.: Urban governance in the post-fordist city. In: Healey P (ed), Managing Cities: The New Urban Context. Wiley, London (1995)

Meyer, M.D.: Transport planning for urban areas: A retrospective look and future prospects. J. Adv. Transport. 34(1):143-171 (2000)

Milwaukee Economic Development Cooperation.: Annual Report. Milwaukee Economic Development Cooperation, Milwaukee (2001)

Mogalle, M.: Management transdisziplinärer Forschungsprozesse (Management of transdisciplinary research processes). Birkhäuser, Basel (2001)

Molina, L.T., Molina, M.J.: Air Quality in the Mexico Megacity-An Integrated Assessment. Alliance for Global Sustainability Bookseries. Kluwer Academic Publishers, Dordrecht (2002)

Myers, D., Banerjee, T.: Toward Greater Heights for Planning. J. Am. Plan. Assoc. 71(2):121-131 (2005)

Nijkamp, P., Ouwersloot, H., Rienstra, S.A.: Sustainable urban transport systems: an expert-based strategic scenario approach. Urban Studies 34(4):693-712 (1997)

Nijkamp, P., van der Burch, M., Vindigni, G.: A comparative institutional evaluation of publicprivate partnerships in Dutch urban land-use and revitalisation projects. Urban Studies 39(10):1865-1880 (2002)

Noteboom, B.: Learning by interaction. J. Manage. Governance 4(1-2):69-92 (2000)

Olkowski, P., Skowron, A.: Rough Set in Knowledge Discovery. Physica-Verlag, Berlin (1998)

Pawlak, Z.: Rough Sets. Kluwer, Dordrecht (1991)

Petts, J.: Evaluating the effectiveness of deliberative processes: waste management case-studies. J. Environ. Plan. Manage. 44(2):207-226 (2001)

Predki, B., Slowinski, J., Stefanowski, J., Susmaga, R., Wilk, S.: ROSE—-software implementation of the rough set theory. In: Polkowski L., Skowron A. (eds), Rough Sets and Current Trends in Computing. Springer, Berlin (1998)

Scholz, R.W., Lang, D., Walter, A.I., Wiek, A., Stauffacher, M.: Transdisciplinary case studies as a means of sustainability learning: historical framework and theory. Int. J. Sustain. Higher Education 7(3):226-251 (2006)

Scholz, R.W., Tietje, O.: Embedded case study methods: integrating quantitative and qualitative knowledge. Sage, Thousand Oaks (2002)

Scott, J.: Social Network Analysis: A Handbook. Sage, London (2000)

Stauffacher, M., Walter, A.I., Lang, D., Wiek, A., Scholz, R.W.: Learning to research environmental problems from a functional socio-cultural constructivism perspective: the transdisciplinary case study approach. Int. J. Sustain. Higher Education 7(3):252-275 (2006) 
Susskind, L., Cruikshank, J.: Consensual Approaches to Resolving Public Disputes. Basic Books, New York (1987)

Szyliowicz, J.S.: Decision-making, intermodal transportation, and sustainable mobility: towards a new paradigm. Int. Social Sci. J. 55(2):185-197 (2003)

Talvitie, A.: Comment on Richard Willson's paper: assessing communicative rationality as a transportation planning paradigm. Transportation 28(2):207-210 (2001)

Tapio, P., Hietanen, O.: Epistemology and public policy: using a new typology to analyse the paradigm shift in Finnish transport futures studies. Futures 34(7):597-620 (2002)

van der Meer, F.B., Edelenbos, J.: Evaluation in multi-actor policy processes: accountability, learning and cooperation. European Evaluation Society Conference: Seville, October 10-12 (2002)

van Egmond, P., Nijkamp, P., Vindigni, G.: A comparative analysis of the performance of urban public transport systems in Europe. Int. Social Sci. J. 55(2):235-247 (2003)

Vigar, G.: Local 'barriers' to environmentally sustainable transport planning. Local Environ. 5(1):19-32 (2000)

Walter, A.I., Scholz, R.W.: Sustainable innovation networks: an empirical study on inter-organisational networks in industrial ecology. Prog. Industrial Ecol. (forthcoming)

Ward, D.: Stakeholder involvement in transport planning: participation and power. Impact Assess. Project Appraisal 19(2):119-130 (2001)

Wiek, A., Binder, C.: Solution spaces for decision-making — a sustainability assessment tool for cityregions. Environ. Impact Assess. Rev. 25(6):589-608 (2005)

Willson, R.: Assessing communicative rationality as a transportation planning paradigm. Transportation 28(1):1-31 (2001)

Yarime, M.: Public coordination of participants' behavior and expectations: an attempt to introduce low-emission vehicles in Tokyo. Shakai-Gijutsu Kenkyu Ronbun-shu (Journal of Science and Technology for Society) 2(1):39-48 (2004)

Yiftachel, O.: Planning and social control: exploring the dark side. J. Plan. Literature 12(4):395-406 (1998)

Yiftachel, O., Huxley, M.: Debating dominance and relevance: notes on the 'communicative turn' in planning theory. Int. J. Urban Regional Res. 24(4):907-913 (2000)

Yin, R.: Case Study Research: Design and Methods. Sage, Beverly Hills (1984)

Zegras, C., Sussman, J., Conklin, C.: Scenario planning for strategic regional transportation planning. J. Urban Plan. Develop. ASCE 130(1):2-13 (2004)

Roland W. Scholz is a full professor at ETH Zurich and holds the chair of Environmental Sciences: Natural and Social Science Interface. His current research field focus on environmental decision making in human-environment interactions. Current topics are complex environmental system analysis and complex problem solving.

Alexander I. Walter is a researcher at ETH Zurich at the Natural and Social Sciences Interface. His research interests include the analysis, evaluation and implementation of transdisciplinary research processes, including collaborative planning methodology and theory. Furthermore, he is developing new methods of strategic and cross-sectoral transdisciplanary planning. 